\title{
Species height and root symbiosis, two factors influencing antiherbivore defense of woody plants in East African savanna
}

\section{R. Thomas Palo ${ }^{1}$, Juan Gowda ${ }^{1}$, Peter Högberg ${ }^{2}$}

Oecologia (1993) 93:322-326

Due to an unfortunate error in the legend of Fig. 1 symbols are reversed. The correct figure legend and symbols are:
Fig. 1. Regression of polyphenols in mature leaves $(\mathrm{mg} / \mathrm{g}$ tannic acid equivalents) against height for $\mathrm{N}_{2}$-fixing ( $\Delta$ ) and non- $\mathrm{N}_{2}$-fixing (•) species. $\mathrm{Y}=17.8-0.7 \times$ height $-3.5 \times \mathrm{N}_{2}$-fixing ability. Polyphenols measured as absorbance of Folin-Ciocalteau reaction at $740 \mathrm{~nm}$ and confirmed by TLC 